\title{
A novel proline-rich $M$-superfamily conotoxin that can simultaneously affect sodium, potassium and calcium currents
}

\author{
Manyi Yang ${ }^{1}$, Yubin Li², Longfei Liư ${ }^{3}$, Maojun Zhou²* \\ 1Department of Hepatobiliary and Pancreatic Surgery, NHC Key Laboratory of Nanobiological Technology, Xiangya Hospital, Central South University, \\ Changsha, Hunan, China. \\ ${ }^{2}$ Department of Oncology, State Local Joint Engineering Laboratory for Anticancer Drugs, NHC Key Laboratory of Cancer Proteomics, Xiangya Hospital, \\ Central South University, Changsha, Hunan, China. \\ ${ }^{3}$ Department of Urology, National Clinical Research Center for Geriatric Disorder, Xiangya Hospital, Central South University, Changsha, Hunan, China.
}

\section{Keywords:}

Conotoxin

Conopeptide

Sodium currents

Potassium currents

Calcium currents

\begin{abstract}
Background: Conotoxins have become a research hotspot in the neuropharmacology field for their high activity and specificity in targeting ion channels and neurotransmitter receptors. There have been reports of a conotoxin acting on two ion channels, but rare reports of a conotoxin acting on three ion channels.
\end{abstract}

Methods: Vr3a, a proline-rich M-superfamily conotoxin from a worm-hunting Conus varius, was obtained by solid-phase synthesis and identified by mass spectrometry. The effects of synthesized Vr3a on sodium, potassium and calcium currents were tested on rat DRG cells by patch clamp experiments. The further effects of $\mathrm{Vr} 3 \mathrm{a}$ on human $\mathrm{Ca}_{\mathrm{v}} 1.2$ and $\mathrm{Ca}_{\mathrm{v}} 2.2$ currents were tested on HEK293 cells.

Results: About $10 \mu \mathrm{M}$ Vr3a has no effects on the peak sodium currents, but can induce a $\sim 10 \mathrm{mV}$ shift in a polarizing direction in the current-voltage relationship. In addition, $10 \mu \mathrm{M}$ Vr3a can increase $19.61 \pm 5.12 \%$ of the peak potassium currents and do not induce a shift in the current-voltage relationship. An amount of $10 \mu \mathrm{M}$ Vr3a can inhibit $31.26 \%$ $\pm 4.53 \%$ of the peak calcium currents and do not induce a shift in the current-voltage relationship. The $\mathrm{IC}_{50}$ value of $\mathrm{Vr} 3 \mathrm{a}$ on calcium channel currents in rat DRG neurons is $19.28 \pm 4.32 \mu \mathrm{M}$. Moreover, $10 \mu \mathrm{M} \mathrm{Vr} 3 \mathrm{a}$ can inhibit $15.32 \% \pm 5.41 \%$ of the human $\mathrm{Ca}_{\mathrm{v}} 1.2$ currents and $12.86 \% \pm 4.93 \%$ of the human $\mathrm{Ca}_{\mathrm{v}} 2.2$ currents.

Conclusions: Vr3a can simultaneously affect sodium, potassium and calcium currents. This novel triple-target conotoxin Vr3a expands understanding of conotoxin functions.

* Correspondence: zhoumaojun@csu.edu.cn https://doi.org/10.1590/1678-9199-JVATITD-2020-0164 Received: 10 November 2020; Accepted: 01 March 2021; Published online: 11 June 2021 


\section{Background}

Conotoxins or conopeptides are marine bioactive peptides derived from more than 700 Cone snails [1,2]. Typical conotoxins contain 10-30 amino acids with multiple disulfide bonds and post-translational modifications [3,4]. Due to the high specificity and selectivity of conotoxins in targeting ion channels and neurotransmitter receptors, conotoxins have become a research hotspot in the neuropharmacology field [5]. One of the calcium channel inhibitors, $\omega$-conotoxin MVIIA (ziconotide), was proved by the United States Food and Drug Administration (FDA) in 2004 for treating intractable pain [6]. Moreover, conotoxins can also be used as molecular probes for ion channel research and drug leads for the therapy of pain, addiction, cardiovascular, epilepsy, cancer and so on [7-9].

M-superfamily is one of the biggest superfamilies and has been found in all the Conus species tested so far [10]. M-superfamily conotoxins mainly contain a Framework III cysteine pattern (CC$\mathrm{C}-\mathrm{C}-\mathrm{CC}$ ) and a highly homologous signal region [11]. Most of the known active $\mathrm{M}$-superfamily conotoxins are $\mu$-conotoxins that block sodium channels with high potency and subtype selectivity [12]. Due to the high inhibitory activity of rat tetrodotoxinresistant sodium currents [13], $\mu$-conotoxin SIIIA was used as a preclinical lead for the treatment of pain [14]. $\mu$-conotoxins can also be used as sodium channel research probes for their high subtype selectivity, and may be used as neuroprotective agents against hypoxia or oxidative stress [15]. In addition to these $\mu$-conotoxins, several other $\mathrm{M}$-superfamily conotoxins were found to inhibit nicotinic acetylcholine receptors or block voltage-gated potassium channels $[10,16]$. M-superfamily conotoxins are further divided into the M-1, M-2, M-3 M-4 and M-5 branch conotoxins, based on the number of amino acids that exist between the fourth and the fifth cysteines [10]. M-1 branch conotoxins have the disulfide connectivity of 1-5, 2-4, 3-6; M-2 branch conotoxins have the disulfide connectivity of 1-6, 2-4, 3-5; while M-4 and M-5 branch conotoxins have the disulfide connectivity of 1-4, 2-5, 3-6 [10].

In our previous study, a specific group of M-superfamily conotoxins was found from a worm-hunting Conus varius [17]. One of these M-superfamily conotoxins, Vr3a, has no sequence homology with other conotoxins, indicating that it may has a specific physiological function. In this study, we tried to figure out the physiological target of Vr3a. The disulfide connectivity of Vr3a was set as 1-4, 2-5, 3-6 according to the disulfide connectivity of other M-4 conotoxins. The Vr3a peptide was obtained by solid-phase synthesis and identified by mass spectrometry. The sodium, potassium and calcium channel physiological activities of Vr3a were tested on rat DRG cells by patch clamp experiments. The further human $\mathrm{Ca}_{\mathrm{v}} 1.2$ and $\mathrm{Ca}_{\mathrm{v}} 2.2$ physiological activities of Vr3a were tested on HEK293 cells.

\section{Methods}

\section{Synthesis of conotoxin Vr3a}

Conotoxin Vr3a, whose amino acid sequence is QGCCPPGVCQMAACNPPPCCP, was synthesized by solidphase polypeptide synthesis. Briefly, conotoxin peptide was assembled on Rink-resin using Fmoc-strategy according to its amino acid sequence. The amino acid residues were coupled using HOBt/HBTU/DIPEA (1:1:0.9) for $2 \mathrm{~h}$ and cleavaged from the resin with regent $\mathrm{R}$ (90\% TFA: 5\% thioanisole: $3 \%$ 1, 2-ethanedithiol: $2 \%$ anisole). Six cysteines were protected by acetamidomethyl (Acm) (Cys3 and 14), methoxytriphenyl (Mmt) (Cys4 and 19) or Triphenylmethyl (Trt) (Cys9 and 20) separately and the three disulfide bonds (3-14, 4-19, 9-20) were successively formed by oxidation. The final oxidized peptide was purified through a C18 reverse phase column $(4.6 \mathrm{~mm} \times 250 \mathrm{~mm}$, 5_m particle diameter, $300 \AA$ ) on 600E HPLC system (Waters, America). The mobile phase used a gradient of $5-50 \%$ solvent $\mathrm{B}$ in $30 \mathrm{~min}$, where solvent $\mathrm{A}$ was $\mathrm{H} 2 \mathrm{O} / 0.1 \%$ TFA and solvent $\mathrm{B}$ was $100 \% \mathrm{CH} 3 \mathrm{CN} / 0.1 \% \mathrm{TFA}$. The flow rate was $1 \mathrm{ml} / \mathrm{min}$ and the absorbance was monitored at $215 \mathrm{~nm}$. The peptide (in $30 \%$ acetonitrile $/ 0.1 \%$ TFA) was treated with a-cyano-4hydroxycinnamic acid (CHCA) and the molecular weight was determined by matrix assisted laser desorption ionization mass spectrum (MALDI-MS) using a REFLEX III time-of-flight mass spectrometer (Bruker Daltonics, America).

\section{Acute separation of DRG cells}

The animal protocols used in this study were evaluated and approved by the Xiangya Hospital Medical ethics committee of Central South University. Sprague-Dawleys (SD) rats were purchased from Hunan SJA Laboratory Animal Co. Ltd. with a quality license. Acutely separated dorsal root ganglion (DRG) cells were prepared from 30-day-old SD rats of either sex [18]. The rats were euthanized and the dorsal root ganglia tissue was removed quickly and cut into small pieces. The ganglia were treated with collagenase (Sigma, USA) followed by trypsin (Sigma, USA). Trypsin inhibitor (Sigma, USA) was added to a final concentration of $1.5 \mathrm{mg} / \mathrm{mL}$ to terminate the enzymatic treatment. After centrifugation, the DRG cells were suspended in essential Dulbecco's modified Eagle's medium (DMEM) with $10 \%$ fetal bovine serum and incubated at $37^{\circ} \mathrm{C}$ in a $\mathrm{CO}_{2}$ incubator for $3 \mathrm{~h}$. Medium DRG cells (diameters $20 \sim 30 \mu \mathrm{m}$ ) were used to record TTX-sensitive and TTX-resistant mixed currents.

\section{Transfection of $\mathrm{Ca}_{\mathrm{v}} \mathrm{1.2}$ and $\mathrm{Ca}_{\mathrm{v}} 2.2$ into HEK293 cells}

HEK293 cells, which were obtained from the Cell Bank of the Chinese Academy of Sciences (Shanghai, China) with STR 
Authentication, were cultured in DMEM with $10 \%$ fetal bovine serum. Plasmids of human $\mathrm{Ca}_{\mathrm{v}} 1.2$ and $\mathrm{Ca}_{\mathrm{v}} 2.2$ were cloned by our lab and were separately transfected into HEK293 cells using Lipofectamine 3000 (Invitrogen).

\section{Intracellular and extracellular solutions for patch clamp}

For recording sodium currents, the intracellular solution contained the following composition: $10 \mathrm{mM} \mathrm{CsCl}, 5 \mathrm{mM} \mathrm{NaCl}_{2}$, 10 mM HEPES, 2 mM Mg-ATP, 135 mM CsF, 5 mM EGTA, $\mathrm{pH}=7.2(\mathrm{CsOH})$, and the extracellular solution contained the following composition: $22 \mathrm{mM} \mathrm{NaCl}, 110 \mathrm{mM}$ Choline- $\mathrm{Cl}, 5$ $\mathrm{mM}$ D-glucose, $10 \mathrm{mM}$ HEPES, $0.8 \mathrm{mM} \mathrm{MgCl}_{2}, 1.8 \mathrm{mM} \mathrm{CaCl}_{2}$, $\mathrm{pH}=7.4(\mathrm{NaOH})$.

For recording potassium currents, the intracellular solution contained the following composition: $120 \mathrm{mM} \mathrm{KCl,} 1 \mathrm{mM}$ $\mathrm{MgCl}_{2}, 5 \mathrm{mM}$ EGTA, $14 \mathrm{mM}$ Phoshocreatine disodium salt, 5 $\mathrm{mM} \mathrm{Na}$-GTP, $\mathrm{pH}=7.2(\mathrm{KOH})$, and the extracellular solution contained the following composition: $1.8 \mathrm{mM} \mathrm{CaCl}_{2}, 135 \mathrm{mM}$ Choline-Cl, $10 \mathrm{mM}$ D-glucose, $10 \mathrm{mM}$ HEPES, $1 \mathrm{mM} \mathrm{MgCl}$, $4.5 \mathrm{mM} \mathrm{KCl}, \mathrm{pH}=7.4(\mathrm{KOH})$.

For recording calcium currents, the intracellular solution contained the following composition: $120 \mathrm{mM} \mathrm{CsCl}, 1 \mathrm{mM} \mathrm{MgCl}_{2}$, $10 \mathrm{mM}$ HEPES, $4 \mathrm{mM}$ Mg-ATP, $0.3 \mathrm{mM} \mathrm{Na}_{2}$-GTP, $10 \mathrm{mM}$ EGTA, $\mathrm{pH}=7.2(\mathrm{CsOH})$, and the extracellular solution contained the following composition: $140 \mathrm{mM}$ TEA-Cl, $2 \mathrm{mM} \mathrm{MgCl}, 5 \mathrm{mM}$ D-glucose, $10 \mathrm{mM}$ HEPES, $10 \mathrm{mM} \mathrm{CaCl}_{2}, \mathrm{pH}=7.4(\mathrm{NaOH})$.

\section{Recording procedures for patch clamp}

To acquire current-voltage (I-V) relationships of sodium channels in DRG cells, test potentials ranged from -120 to $+100 \mathrm{mV}$ in $10 \mathrm{mV}$ steps from a holding potential of $-120 \mathrm{mV}$ using EPC-10 (HEKA, Germany). For the activation curve of sodium channels, test potentials ranged from -80 to $+100 \mathrm{mV}$ in $5 \mathrm{mV}$ steps from a holding potential of $-120 \mathrm{mV}$. For the inactivation curve of sodium channels, test potentials ranged from -120 to $+40 \mathrm{mV}$ in $5 \mathrm{mV}$ steps from a holding potential of $-120 \mathrm{mV}$ for 1000 $\mathrm{ms}$, then stepped to $0 \mathrm{mV}$ for $50 \mathrm{~ms}$, and finally stepped to -120 $\mathrm{mV}$ for $150 \mathrm{~ms}$. For the recovery curve of sodium channels, test potential was stepped to $-10 \mathrm{mV}$ for $5 \mathrm{~ms}$ to inactivate the sodium current, then stepped to $-120 \mathrm{mV}$ for different times to allow the sodium current to recover, and finally stepped to -10 $\mathrm{mV}$ for $50 \mathrm{~ms}$ to detect the sodium current. $\mathrm{V}_{50}$ was calculated by GraphPad Prism version 5.01 and shifts were calculated by the numerical change of $\mathrm{V}_{50}$ for activation and inactivation curves (Additional files 1 and 2).

To acquire current-voltage (I-V) relationships of potassium channels in DRG cells, test potentials ranged from -80 to +80 $\mathrm{mV}$ in $10 \mathrm{mV}$ steps from a holding potential of $-80 \mathrm{mV}$ using EPC-10 (HEKA, Germany).

To acquire current-voltage (I-V) relationships of calcium channels in DRG cells, test potentials ranged from -60 to +60 $\mathrm{mV}$ in $10 \mathrm{mV}$ steps from a holding potential of $-60 \mathrm{mV}$ using
EPC-10 (HEKA, Germany). The calcium currents of $\mathrm{Ca}_{\mathrm{v}} 1.2$ and $\mathrm{Ca}_{\mathrm{v}} 2.2$ were induced by a $400 \mathrm{~ms}$ depolarization of $10 \mathrm{mV}$ from a holding potential of $-60 \mathrm{mV}$.

Micropipettes were pulled from borosilicate glass capillary tubing (1.0-2.0 mm diameter) by using a P97 puller (Sutter Instrument Co.). After micropipettes contacting with the cell, negative pressure suction was applied to form $G \Omega$ sealing. After the formation of G $\Omega$ sealing, the fast capacitance was compensated, and then the negative pressure was applied to break the cell membrane to form the whole cell recording mode. The resistances of micropipettes were 2-5 M $\Omega$. Slow capacitance was compensated and the membrane capacitance and series resistance $(<15 \mathrm{M} \Omega)$ are recorded. The experimental data were collected by EPC-10 amplifier (HEKA, Germany) and analyzed in software patchmaster (HEKA, Germany).

\section{Data analysis}

Software GraphPad Prism version 5.01 was used to statistically analyze the data and plot the curves. Data are presented as the mean values and standard deviation. For the experimental repetition times, electrophysiological experiments in DRG cells were repeated 3 times $(n=3)$ and electrophysiological experiments in HEK293 cells were repeated 8 times $(n=8)$.

\section{Results}

\section{Synthesis, purification and identification of conotoxin Vr3a}

Vr3a gene was identified from a worm-hunting Conus varius by PCR. The cDNA and amino acids of Vr3a were shown in Figure 1. The predicted mature region of Vr3a contains six cysteines, which could form three pairs of disulfide bonds. According to the disulfide bonds of other M-4 and M-5 branch conotoxins [10], the mature Vr3a peptide was synthesized with three pairs of disulfide bonds (1-4, 2-5, 3-6) using a solid-phase polypeptide synthesis method. The synthesized crude peptide was purified by HPLC and identified by mass spectrometry (Figure $2 \mathrm{~A}$ and 2B). The average mass of the synthesized peptide was 2068.7 $\mathrm{Da}$, which was consistent with the molecular weight of $\mathrm{Vr} 3 \mathrm{a}$, indicating that Vr3a with three disulfide bonds was successfully synthesized. The monoisotopic mass spectrum of the Vr3a was shown in Additional file 3.

\section{Effects of Vr3a on DRG sodium, potassium and calcium currents}

Vr3a was tested its electrophysiological activities on the acute isolated rat DRG cells using patch clamp. For the sodium channels, $10 \mu \mathrm{M}$ Vr3a has no effects on the peak of the sodium currents $(\mathrm{n}=3$, Figure $3 \mathrm{~A}$ and $3 \mathrm{~B})$, but can induce a $\sim 10 \mathrm{mV}$ shift in a polarizing direction in the current-voltage relationship (Figure 3C). $10 \mu \mathrm{M}$ Vr3a can also induce a negative $\sim 10 \mathrm{mV}$ shift in the activation curve (Figure 3D) and a negative $\sim 5 \mathrm{mV}$ shift 
1 Atg TTG AAg ATG GgA GTG GTG CTA TTC ACC GTT CTG GTC CTG TTT CCC CTG GCA ACA CTC

$\begin{array}{lllllllllllllllllllll}1 & \mathbf{M} & \mathbf{L} & \mathbf{K} & \mathbf{M} & \mathbf{G} & \mathbf{V} & \mathbf{V} & \mathbf{L} & \mathbf{F} & \mathbf{T} & \mathbf{V} & \mathbf{L} & \mathbf{V} & \mathbf{L} & \mathbf{F} & \mathbf{P} & \mathbf{L} & \mathbf{A} & \mathbf{T} & \mathbf{L}\end{array}$

61 CAT CTG GAT GCA GAA CAA CCT GTA GAA CGA TAT GCG GAG AAC AAA CAG GAC ATC AAC CCA

$\begin{array}{lllllllllllllllllllll}21 & \mathbf{H} & \mathbf{L} & \mathbf{D} & \mathbf{A} & E & Q & P & V & E & R & Y & A & E & N & K & Q & D & I & N & P\end{array}$ 121 GAC CAA AGG AGT GGA TTC CTA ACG TTT GCT CTG AGG CAG GGC TGC TGC CCT CCT GGG GTG

\begin{tabular}{lllllllllllllllllllllll}
41 & $D$ & $Q$ & $R$ & $S$ & $G$ & $F$ & $L$ & $T$ & $F$ & $A$ & $L$ & $R$ & $\mathrm{Q}$ & $\mathrm{G}$ & $\mathrm{C}$ & $\mathrm{C}$ & $\mathrm{P}$ & $\mathrm{P}$ & $\mathrm{G}$ & $\mathrm{V}$ \\
\hline
\end{tabular}

181 TGC CAA ATG GCG GCG TGT AAT CCT CCT CCT TGC TGC CCA TAG

$\begin{array}{lllllllllllllll}61 & \mathrm{C} & \mathrm{Q} & \mathrm{M} & \mathrm{A} & \mathrm{A} & \mathrm{C} & \mathrm{N} & \mathrm{P} & \mathrm{P} & \mathrm{P} & \mathrm{C} & \mathrm{C} & \mathrm{P} & *\end{array}$

Figure 1. The full-length cDNA and putative amino acid sequence of $\mathrm{Vr} 3 \mathrm{a}$. The signal region is in bold, pro-region is in italics and mature region is underlined.

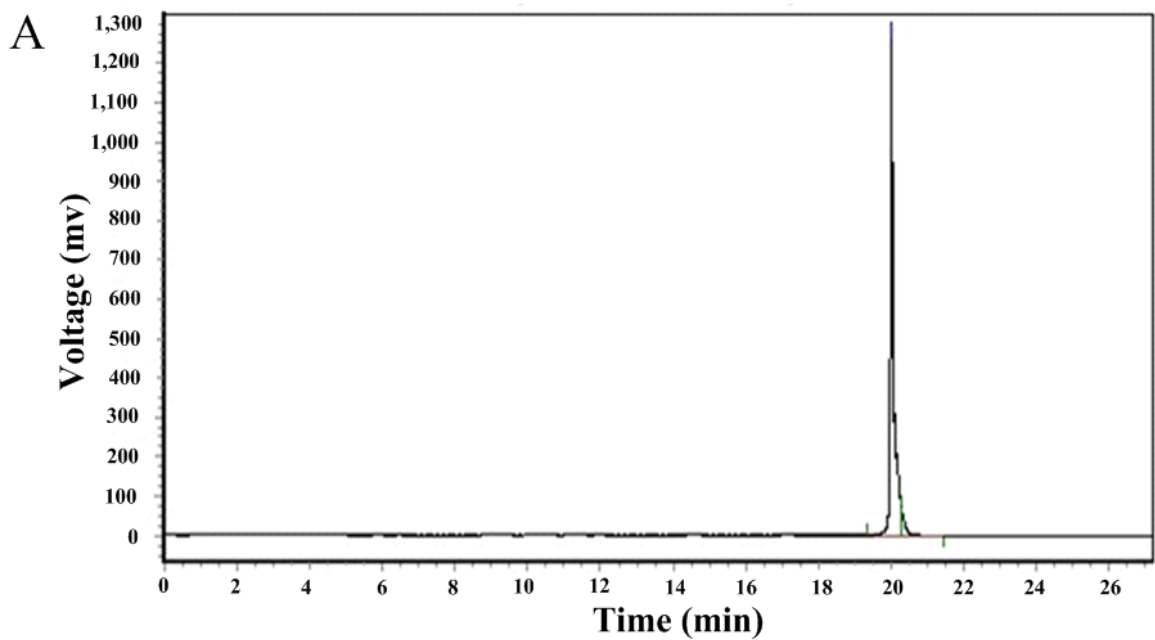

2069.7

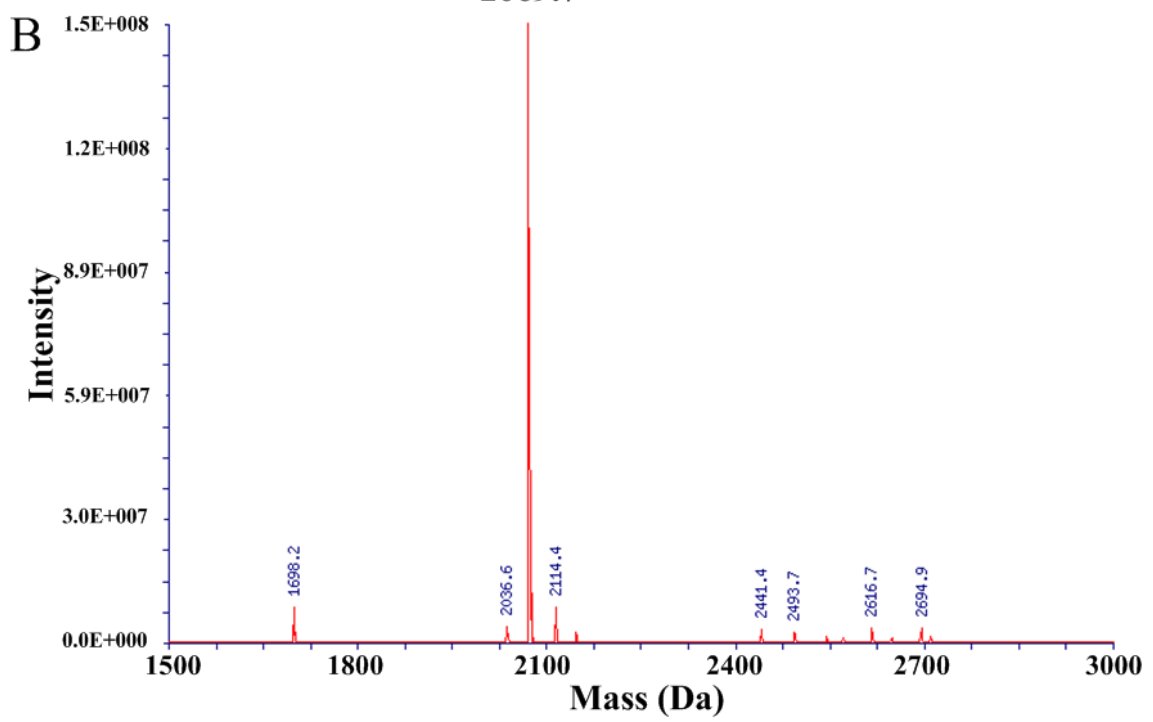

Figure 2. HPLC chromatogram and mass spectrum of the synthesized peptide $\mathrm{Vr} 3 \mathrm{a}$. (A) Reverse phase HPLC purification of the synthesized peptide $\mathrm{Vr} 3 \mathrm{a}$. The retention time is 20.03 minutes and the $B \%$ is $~ 60 \%$. (B) Mass spectrum of the synthesized peptide $\mathrm{Vr} 3 \mathrm{a}$. 
A

Control

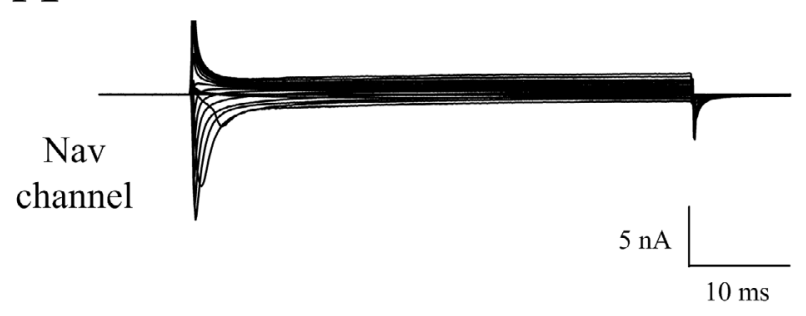

C

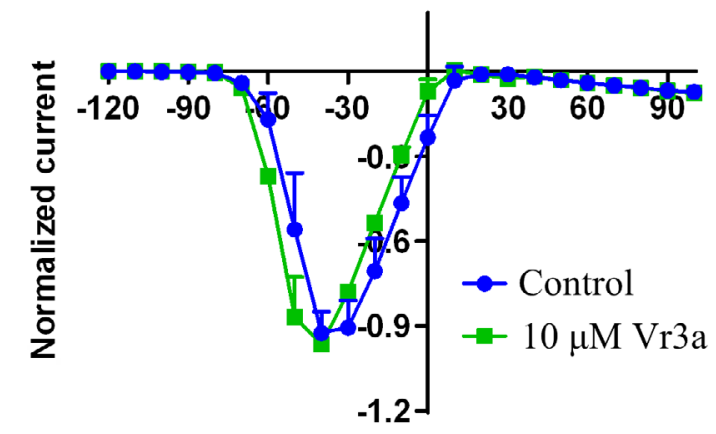

Membrane potential $(\mathrm{mV})$

$\mathrm{E}$

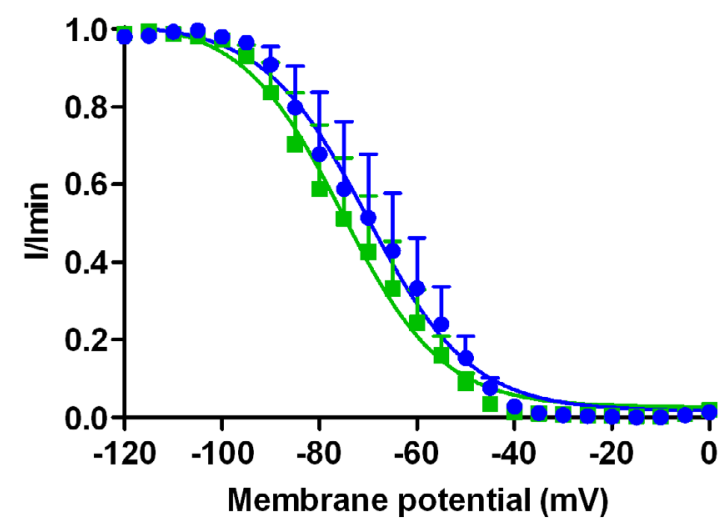

B

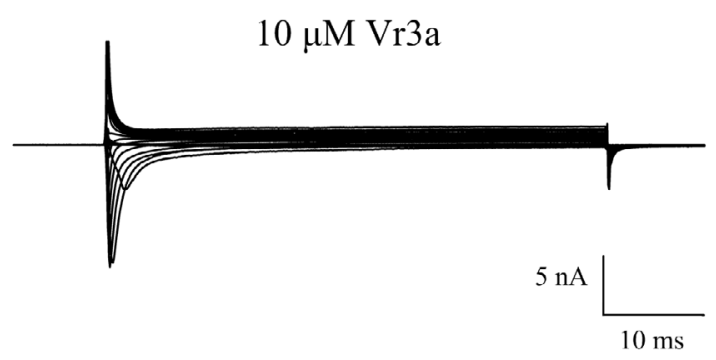

D

Activation

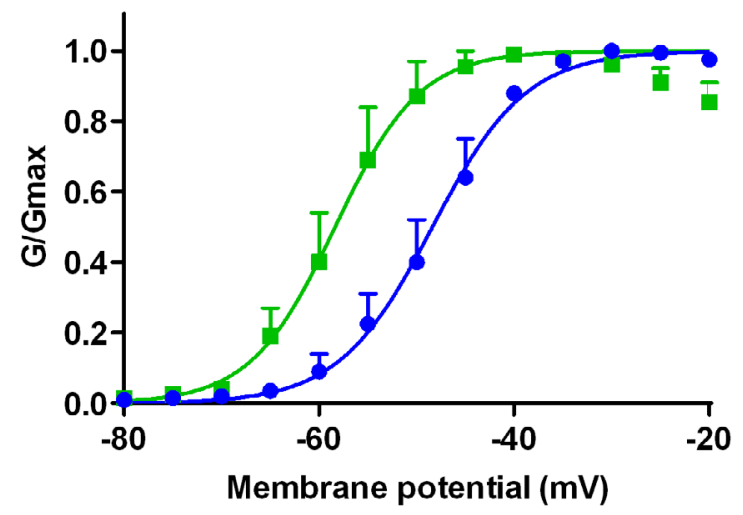

F

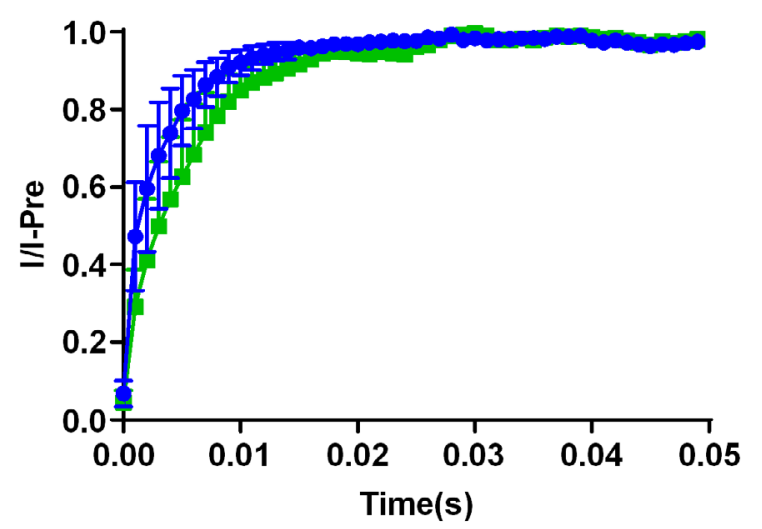

Figure 3. Effects of $10 \mu \mathrm{M} \mathrm{Vr3a}$ on sodium channel currents in rat DRG neurons. Effects of vehicle (A) control and (B) $10 \mu \mathrm{M}$ Vr3a on sodium channel currents in rat DRG neurons. Effects of $10 \mu \mathrm{MVr}$ a on $(\mathbf{C})$ the current-voltage (I-V) relationships, (D) activation, (E) inactivation and (F) recovery of sodium channel currents in DRG neurons.

in the inactivation curve (Figure 3E). For the recovery curve, 10 $\mu \mathrm{M}$ Vr3a can induce a $\sim 0.002$ second shift in delaying sodium channel recovery (Figure 3F).

For the calcium channels in DRG cells, $10 \mu \mathrm{M}$ Vr3a can inhibit $31.26 \% \pm 4.53 \%$ of the peak calcium currents and do not induce a shift in the current-voltage relationship $(n=3$, Figure $4 \mathrm{~A}$ and $4 \mathrm{~B}$ ). The $\mathrm{IC}_{50}$ value of $\mathrm{Vr} 3 \mathrm{a}$ on calcium channel currents in rat DRG neurons is $19.28 \pm 4.32 \mu \mathrm{M}(\mathrm{n}=3$, Figure $4 \mathrm{C})$. For the potassium channels in DRG cells, $10 \mu \mathrm{M}$ Vr3a can increase $19.61 \pm 5.12 \%$ of the peak potassium currents and do not induce a shift in the current-voltage relationship $(n=3$, Figure $4 \mathrm{D}$ and $4 \mathrm{E})$.

\section{Effects of Vr3a on human $\mathrm{Ca}_{\mathrm{v}} 1.2$ and $\mathrm{Ca}_{\mathrm{v}} 2.2$ currents}

Plasmids of human $\mathrm{Ca}_{\mathrm{v}} 1.2$ and $\mathrm{Ca}_{\mathrm{v}} 2.2$ were transfected into HEK293 cells respectively, and Vr3a were tested on the human $\mathrm{Ca}_{\mathrm{v}} 1.2$ and $\mathrm{Ca}_{\mathrm{v}} 2.2$. As shown in Figure 5, $10 \mu \mathrm{M}$ Vr3a can inhibit $15.32 \% \pm 5.41 \%$ of the human $\mathrm{Ca}_{\mathrm{v}} 1.2$ currents $(\mathrm{n}=8$, Figure $5 \mathrm{~A}$ ), and $500 \mathrm{nM}$ Nifedipine was used as a positive control. $10 \mu \mathrm{M}$ Vr3a can inhibit $12.86 \% \pm 4.93 \%$ of the human $\mathrm{Ca}_{\mathrm{v}} 2.2$ currents ( $\mathrm{n}=8$, Figure $5 \mathrm{~B}$ ), and $100 \mu \mathrm{M} \mathrm{CdCl} 2$ was used as a positive control. 
A

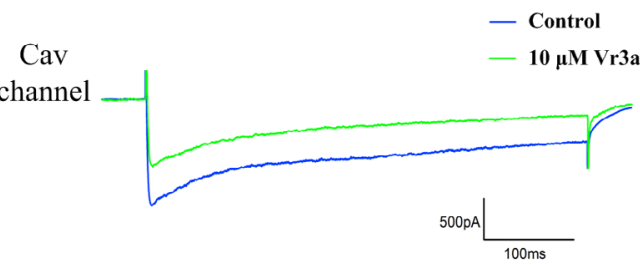

$\mathrm{D}$

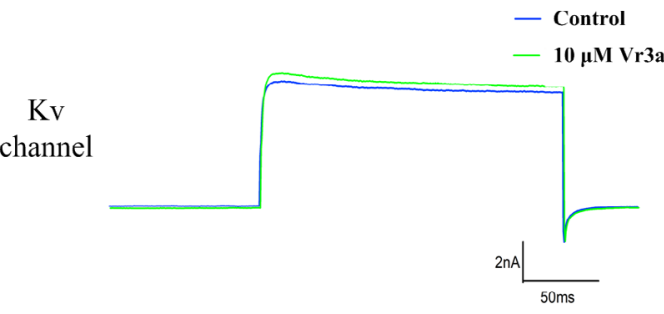

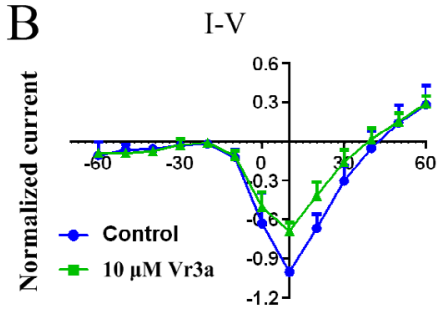

Membrane Potential (mV)

$\mathrm{E}$

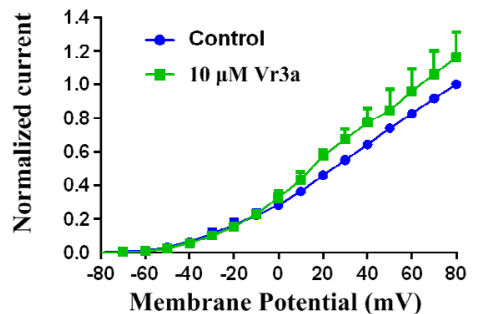

Figure 4. Effects of $10 \mu \mathrm{MVr}$ Va on potassium and calcium channel currents in rat DRG neurons. (A) Effects of $10 \mu \mathrm{M} V \mathrm{r} 3 \mathrm{a}$ on calcium channel currents in rat DRG neurons. (B) Effects of $10 \mu \mathrm{M} V r 3 a$ on the current-voltage $(I-V)$ relationships of calcium channel currents in DRG neurons. (C) The IC $C_{50}$ value of $V r 3 a$ on calcium channel currents in rat DRG neurons. (D) Effects of $10 \mu \mathrm{MVr}$ Va on potassium channel currents in rat DRG neurons. (E) Effects of $10 \mu \mathrm{M} V \mathrm{r} 3 \mathrm{a}$ on the current-voltage (I-V) relationships of potassium channel currents in DRG neurons.
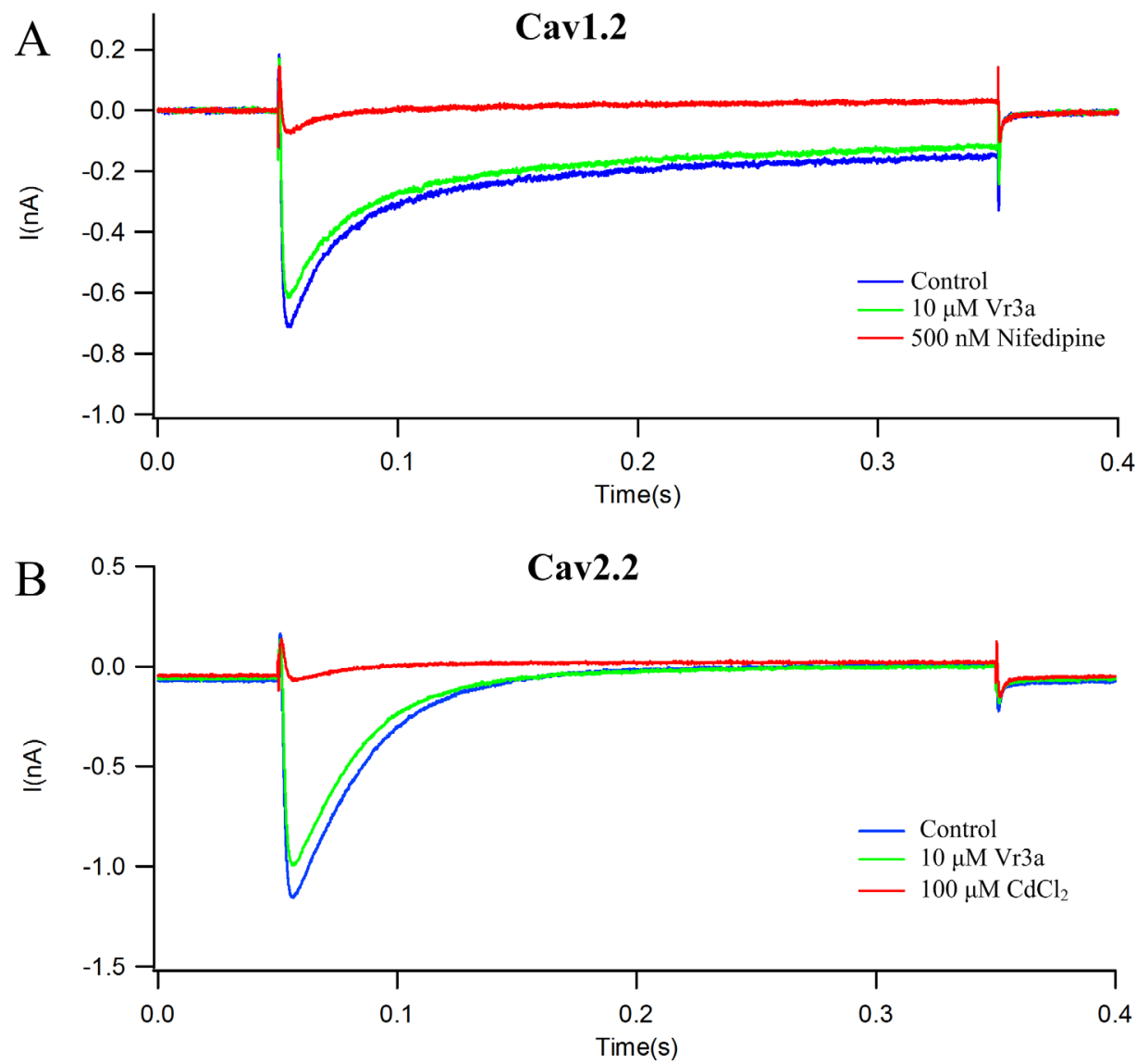

Figure 5. Effects of $10 \mu \mathrm{M} \mathrm{Vr3a}$ on human $\mathrm{Ca}_{\mathrm{v}} 1.2$ and $\mathrm{Ca}_{\mathrm{v}} 2.2$ currents in HEK293 cells. (A) Effects of vehicle control, positive control (500 nM nifedipine) and $10 \mu \mathrm{M}$ Vr3a on human $\mathrm{Ca}_{v} 1.2$ currents. (B) Effects of vehicle control, positive control (100 $\left.\mu \mathrm{M} \mathrm{CdCl}\right)$ and $10 \mu \mathrm{M} \mathrm{Vr} 3 \mathrm{a}$ on human Ca 2.2 currents. 


\section{Discussion}

Conotoxins that effect on sodium, potassium or calcium channels can be used as neuropharmacology research tools or drug leads. For the sodium channels, $\mu$ - and $\mu \mathrm{O}$-conotoxins, which specifically target different voltage-gated sodium channel subtypes, can be used as analgesic compounds for pain therapy [19]. Among the nine functional $\mathrm{Na}_{\mathrm{v}}$ subtypes, $\mathrm{Na}_{\mathrm{v}} 1.7$ and $\mathrm{Na}_{\mathrm{v}} 1.8$ were mainly involved in inflammatory pain, neuropathic pain and transduction of nociceptive information [20,21]. Therefore, the $\mathrm{Na}_{\mathrm{v}} 1.7$ inhibitor $\mu$-conotoxin SxIIIC and the $\mathrm{Na}_{\mathrm{v}} 1.8$ inhibitors $\mu$-conotoxin TsIIIA, $\mu \mathrm{O}$-conotoxin MrVIB, and MfVIA are promising drugs for treating pain [22-25]. For the potassium channels, the conotoxin inhibitors are used in neuroprotection, cardioprotection or anticancer [26-28]. $\mathrm{kM}$-conotoxin RIIIK, which inhibits human $\mathrm{K}_{\mathrm{v}} 1.2$, can reduce ischemia/reperfusioninduced infarction in rats $[29,30]$. For the calcium channels, the conotoxin inhibitors of calcium channels are used in the treatment of absence seizures, chronic pain or neurological disorders [31]. The most famous conotoxin, $\omega$-conotoxin MVIIA, which inhibits $\mathrm{Ca}_{\mathrm{v}} 2.2$ currents, is used clinically for treating chronic pain [32]. According to the results in this study, Vr3a may be used as a drug lead of analgesics for its calcium current inhibitory activity, but its additional sodium channel shift activity and potassium current increase activity may introduce additional side effects or other unknown physiological effects, which should be studied in depth in the future.

Unlike the $\mu$-conotoxins that inhibit sodium currents, Vr3a does not inhibit sodium currents but can induce a $\sim 10 \mathrm{mV}$ shift in the current-voltage relationship, suggesting that $\mathrm{Vr} 3$ a may be a gating modifier that interact with the voltage-sensing domains of $\mathrm{Na}_{\mathrm{v}}$ channels [33]. Similar to the $\omega$-conotoxin that inhibit calcium currents, $\mathrm{Vr} 3 \mathrm{a}$ inhibit calcium currents and does not induce a shift in the current-voltage relationship, suggesting that Vr3a may occupy the binding pocket to block calcium channels and does not interact with the voltage-sensing domains [34]. Unlike the $\kappa M$-conotoxin that inhibit potassium currents, Vr3a can increase the potassium currents and the mechanism needs further study, which may be related to cell excitability [35].

Several conotoxins have been reported to target two different ion channels. For example, $\mu$-conotoxin CnIIIC, an inhibitor of $\mathrm{Na}_{\mathrm{v}} 1.2$ and $\mathrm{Na}_{\mathrm{v}} 1.4$, can also inhibit neuronal nicotinic acetylcholine receptors [36]. A J-superfamily conotoxin pl14a can inhibit $\mathrm{K}_{\mathrm{v}} 1.6$ and nicotinic acetylcholine receptors [37]. An $\mathrm{O}$-superfamily conotoxin $\mathrm{SO} 3$ can inhibit both neuronal sodium and potassium currents in cultured rat hippocampal neuron [38]. Two conotoxins MrVIA and MrVIB can both affect sodium and calcium currents in Lymnaea neurons [39]. In addition to conotoxins, other peptide toxins have also been reported to target multiple ion channels. For example, two spider toxins, Tapla and Tap2a, can inhibit $\mathrm{Na}_{\mathrm{v}}$ and $\mathrm{Ca}_{\mathrm{v}} 3$ channels at nanomolar to micromolar concentration [40]. With the expansion of ion channel research, more toxins like Vr3a targeting different types of ion channels may be discovered in the future.

Vr3a (QGCCPPGVCQMAACNPPPCCP) is a proline-rich $\mathrm{M}$-superfamily conotoxin from the worm-hunting Conus varius. Six of its 21 amino acids are proline, especially four proline at the C-terminal. Vr3a has no sequence similarity with conotoxins from other species, and may be derived from conotoxins of the same Conus species by amino acid insertion as the third loop of $\mathrm{Vr} 3 \mathrm{e}, \mathrm{Vr} 3 \mathrm{~d}, \mathrm{Vr} 3 \mathrm{c}, \mathrm{Vr} 3 \mathrm{~b}$ and $\mathrm{Vr} 3 \mathrm{a}$ is L, SP, DPP, NPP and NPPP (Table 1). We speculate that an evolutionary selection pressure for some kind of physiological functions makes the toxin accumulate proline. However, proline is not a key amino acid for some conotoxins affecting sodium channels, potassium channels and calcium channels, such as $\mathrm{kM}$-RIIIJ affecting Kv1.2 channels [30], $\mu \mathrm{O}$-MfVIA affecting Nav1.8 channels [41] and $\omega$-MVIIC affecting calcium channels [42]. Therefore, whether Vr3a has other physiological functions or proline has unknown interactions with sodium channels, potassium channels or calcium channels need to be studied in the future research. Different from other target-specific conotoxins with nanomolar effective concentration, the effects of $\mathrm{Vr} 3 \mathrm{a}$ on sodium, potassium or calcium currents are weak even at $10 \mu \mathrm{M}$, whether Vr3a affects other calcium subtypes or other ion channels needs further research.

\section{Conclusions}

In summary, this study provides an identification of a novel three-target conotoxin, Vr3a. An amount of $10 \mu \mathrm{M}$ Vr3a can induce a $\sim 10 \mathrm{mV}$ shift in the current-voltage relationship of sodium channels, increase $19.61 \% \pm 5.12 \%$ of the peak potassium currents, and inhibit $31.26 \% \pm 4.53 \%$ of the peak calcium currents in rat DRG cells. In addition, $10 \mu \mathrm{M}$ Vr3a can inhibit $15.32 \% \pm$ $5.41 \%$ of the human $\mathrm{Ca}_{\mathrm{v}} 1.2$ currents and $12.86 \% \pm 4.93 \%$ of the human $\mathrm{Ca}_{\mathrm{v}} 2.2$ currents. This novel M-superfamily conotoxin Vr3a, which has three physiological targets and no sequence homology with all other conotoxins, is a new addition to the research on application of conotoxins. 


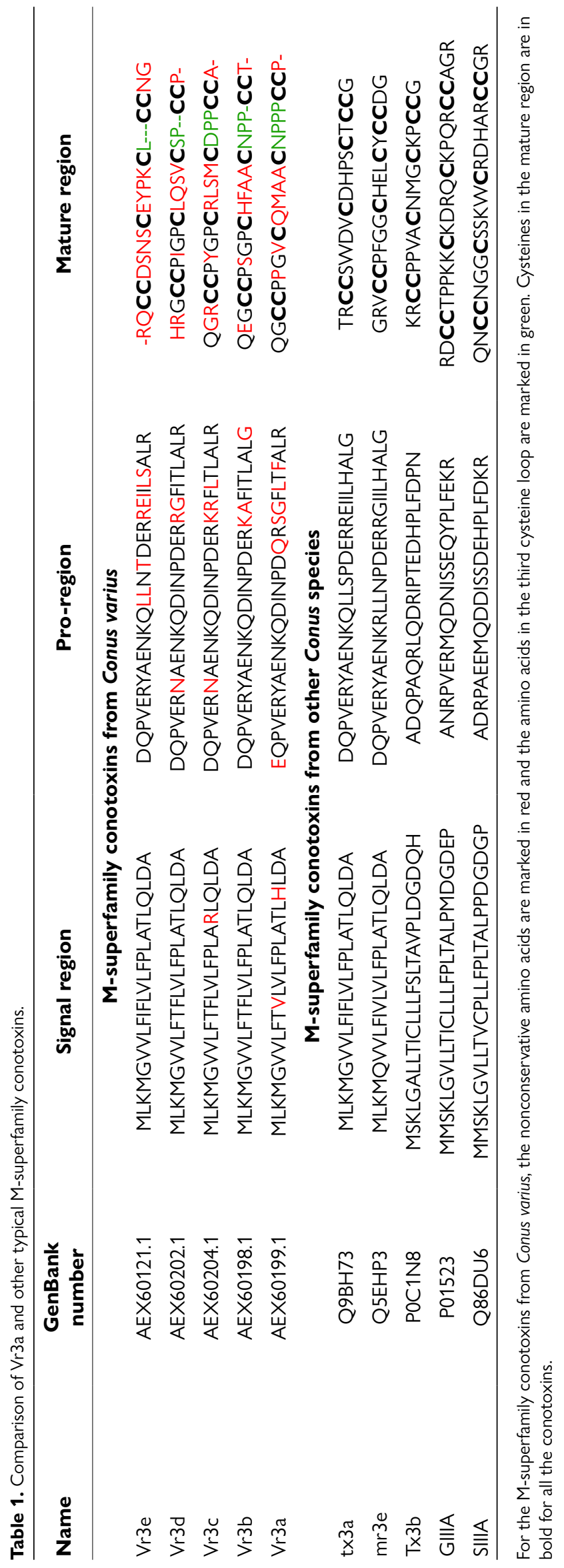




\section{Abbreviations}

Acm: acetamidomethyl; DRG: dorsal root ganglion; FDA: Food and Drug Administration; I-V: current-voltage; MALDI-MS: matrix assisted laser desorption ionization mass spectrum; Mmt: methoxytriphenyl; SD: Sprague-Dawleys; Trt: triphenylmethyl.

\section{Availability of data and materials}

All data generated or analyzed during this study are included in this published article.

\section{Funding}

This research was funded by the National Natural Science Foundation of China (81703412) and Natural Science Foundation of Hunan Province (2018JJ3830).

\section{Competing interests}

The authors declare that they have no competing interests.

\section{Authors' contributions}

$\mathrm{MZ}$ was responsible for conceptualization, and design of the study. MY, YL and LL carried out the experiments. MY conducted data curation and drafted the manuscript. MZ was in charge of the manuscript editing. MY and MZ were responsible for funding acquisition. All authors read and approved the final manuscript.

\section{Ethics approval}

All animal procedures were performed according to the approved protocol of the Xiangya Hospital Medical Ethics Committee of Central South University (approval reference n. 201703515).

\section{Consent for publication}

Not applicable.

\section{Supplementary material}

The following online material is available for this article:

Additional file 1. Effects of $10 \mu \mathrm{M}$ Vr3a (Vr3-NPPP01) on the activation of sodium channel currents in DRG neurons.

Additional file 2. Effects of $10 \mu \mathrm{M}$ Vr3a (Vr3-NPPP01) on the inactivation of sodium channel currents in DRG neurons.

Additional file 3. Monoisotopic molecular mass spectrum of $\mathrm{Vr} 3 \mathrm{a}$.

\section{References}

1. Gallo A, Boni R. Tosti E. Neurobiological activity of conotoxins via sodium channel modulation. Toxicon. 2020 Nov; 187:47-56.

2. Gao B, Peng C, Yang J, Yi Y, Zhang J, Shi Q. Cone Snails: A Big Store of Conotoxins for Novel Drug Discovery. Toxins (Basel). 2017 Dec;9(12):397.

3. Kennedy AC, Belgi A, Husselbee BW, Spanswick D, Norton RS, Robinson AJ. a-Conotoxin Peptidomimetics: Probing the Minimal Binding Motif for Effective Analgesia. Toxins (Basel). 2020 Aug 6;12(8):505.
4. Gaza JT, Sampaco AB 3rd, Custodio KKS, Nellas RB. Conformational dynamics of [Formula: see text]-conotoxin PnIB in complex solvent systems. Mol Divers. 2020 Nov;24(4):1291-9.

5. Morales Duque H, Campos Dias S, Franco OL. Structural and Functional Analyses of Cone Snail Toxins. Mar Drugs. 2019 Jun 21;17(6): 370.

6. Bjørn-Yoshimoto WE, Ramiro IBL, Yandell M, Mclntosh JM, Olivera BM, Ellgaard L, et al. Curses or Cures: A Review of the Numerous Benefits Versus the Biosecurity Concerns of Conotoxin Research. Biomedicines. 2020 Jun 22;8(8):235.

7. Jin $\mathrm{AH}$, Muttenthaler M, Dutertre S, Himaya SWA, Kaas Q, Craik DJ, et al. Conotoxins: Chemistry and Biology. Chem Rev. 2019 Nov 13;119(21):11510-49.

8. Fu Y, Li C, Dong S, Wu Y, Zhangsun D, Luo S. Discovery Methodology of Novel Conotoxins from Conus Species. Mar Drugs. 2018 Nov;16(11):417.

9. Bonci A, Carlezon WAJr. lon channels and intracellular signaling proteins as potential targets for novel therapeutics for addictive and depressive disorders. Pharmacol Ther. 2005 Oct;108(1):65-75.

10. Jacob RB, McDougal OM. The M-superfamily of conotoxins: a review. Cell Mol Life Sci. 2010 Jan;67(1):17-27.

11. Zhou M, Wang L, Wu Y, Zhu X, Feng Y, Chen Z, et al. Characterizing the evolution and functions of the M-superfamily conotoxins. Toxicon. 2013 Dec 15;76:150-9.

12. Norton RS. Mu-conotoxins as leads in the development of new analgesics. Molecules. 2010 Apr 19;15(4):2825-44.

13. Wang CZ, Zhang H, jiang H, Lu W, Zhao ZQ, Chi CW. A novel conotoxin from Conus striatus, mu-SIIIA, selectively blocking rat tetrodotoxinresistant sodium channels. Toxicon. 2006 Jan;47(1):122-32.

14. Lewis RJ. Conotoxins: molecular and therapeutic targets. Prog Mol Subcell Biol. 2009;46:45-65.

15. Ekberg J, Craik DJ, Adams DJ. Conotoxin modulation of voltage-gated sodium channels. Int J Biochem Cell Biol. 2008;40:2363-8.

16. Zhou M, Wang L, Wu Y, Liu J, Sun D, Zhu X, et al. Soluble expression and sodium channel activity of It16a, a novel framework $X V I$ conotoxin from the M-superfamily. Toxicon. 2015 May;98:5-11.

17. Yang $M$, Zhou M. Insertions and Deletions Play an Important Role in the Diversity of Conotoxins. Protein J. 2020 Apr;39(2):190-5.

18. Li S, An J, Sun CK, Li ZW. [Inhibitory effect of caffeine on GABA-activated current in acutely isolated rat dorsal root ganglion neurons]. Sheng $\mathrm{Li}$ Xue Bao. 2004 Jun 25;56(3):384-8.

19. Tosti E, Boni R, Gallo A. $\mu$-Conotoxins Modulating Sodium Currents in Pain Perception and Transmission: A Therapeutic Potential. Mar Drugs. 2017 Oct;15(10):295.

20. Brouwer BA, Merkies IS, Gerrits MM, Waxman SG, Hoeijmakers JG, Faber CG. Painful neuropathies: the emerging role of sodium channelopathies. J Peripher Nerv Syst. 2014 Jun;19(2):53-65.

21. Hameed $\mathrm{S} . \mathrm{Na}(\mathrm{v}) 1.7$ and $\mathrm{Na}(\mathrm{v}) 1.8$ : Role in the pathophysiology of pain Mol Pain. 2019 Jan-Dec;15:1744806919858801.

22. Yang M, Zhou M. $\mu$-conotoxin TsIIIA, a peptide inhibitor of human voltagegated sodium channel hNa(v)1.8. Toxicon. 2020 Oct 30;186:29-34.

23. McMahon KL, Tran HNT, Deuis JR, Lewis RJ, Vetter I, Schroeder CI. Discovery, Pharmacological Characterisation and NMR Structure of the Novel $\mu$-Conotoxin SxIIIC, a Potent and Irreversible $\mathrm{Na}(\mathrm{V})$ Channel Inhibitor. Biomedicines. 2020 Oct 2;8(10):391.

24. Vetter I, Dekan Z, Knapp O, Adams DJ, Alewood PF, Lewis RJ. Isolation, characterization and total regioselective synthesis of the novel $\mu \mathrm{O}$ conotoxin MfVIA from Conus magnificus that targets voltage-gated sodium channels. Biochem Pharmacol. 2012 Aug 15;84(4):540-8.

25. Ekberg J, Jayamanne A, Vaughan CW, Aslan S, Thomas L, Mould J, et al.. muO-conotoxin MrVIB selectively blocks Nav1.8 sensory neuron specific sodium channels and chronic pain behavior without motor deficits. Proc Natl Acad Sci U S A. 2006 Nov 7;103(45):17030-5.

26. Heading CE. Conus peptides and neuroprotection. Curr Opin Investig Drugs. 2002 Jun;3(6):915-20.

27. Twede VD, Miljanich G, Olivera BM, Bulaj G. Neuroprotective and cardioprotective conopeptides: an emerging class of drug leads. Curr Opin Drug Discov Devel. 2009 Mar;12(2):231-9. 
28. Dave K, Lahiry A. Conotoxins: review and docking studies to determine potentials of conotoxin as an anticancer drug molecule. Curr Top Med Chem. 2012;12(8):845-51.

29. Ferber M, Al-Sabi A, Stocker M, Olivera BM, Terlau H. Identification of a mammalian target of kappaM-conotoxin RIIIK. Toxicon. 2004 Jun 15;43(8):915-21.

30. Chen P, Dendorfer A, Finol-Urdaneta RK, Terlau H, Olivera BM. Biochemical characterization of kappaM-RIIIJ, a Kv1.2 channel blocker: evaluation of cardioprotective effects of kappaM-conotoxins. J Biol Chem. 2010 May 14;285(20):14882-9.

31. Patel R, Montagut-Bordas C, Dickenson AH. Calcium channel modulation as a target in chronic pain control. Br J Pharmacol. 2018 Jun;175(12):2173-84.

32. Adams DJ, Berecki G. Mechanisms of conotoxin inhibition of $\mathrm{N}$-type (Ca(v)2.2) calcium channels. Biochim Biophys Acta. 2013;1828(7):1619-28.

33. Bosmans F, Rash L, Zhu S, Diochot S, Lazdunski M, Escoubas P, et al. Four novel tarantula toxins as selective modulators of voltage-gated sodium channel subtypes. Mol Pharmacol. 2006 Feb;69(2):419-29.

34. Bourinet $\mathrm{E}$, Zamponi GW. Block of voltage-gated calcium channels by peptide toxins. Neuropharmacology. 2017 Dec;127:109-15.

35. Cholanian M, Wealing J, Levine RB, Fregosi RF. Developmental nicotine exposure alters potassium currents in hypoglossal motoneurons of neonatal rat. J Neurophysiol. 2017 Apr 1;117(4):1544-52.
36. Favreau P, Benoit E, Hocking HG, Carlier L, D'hoedt D, Leipold E, et al. A novel $\mu$-conopeptide, CnllIC, exerts potent and preferential inhibition of $\mathrm{NaV1.2/1.4}$ channels and blocks neuronal nicotinic acetylcholine receptors. Br J Pharmacol. 2012 Jul;166(5):1654-68.

37. Imperial JS, Bansal PS, Alewood PF, Daly NL, Craik DJ, Sporning A, et al. A novel conotoxin inhibitor of Kv1.6 channel and nAChR subtypes defines a new superfamily of conotoxins. Biochemistry. 2006 Jul 11;45(27):8331-40.

38. Li Z, He XP, Xie ZP, Dai QY, Huang PT. Effect of new O-superfamily conotoxin $\mathrm{SO} 3$ on sodium and potassium currents of cultured hippocampal neurons. Brain Res. 2003 Mar 7;965(1-2):155-8.

39. Fainzilber M, van der Schors R, Lodder JC, Li KW, Geraerts WP, Kits KS. New sodium channel-blocking conotoxins also affect calcium currents in Lymnaea neurons. Biochemistry. 1995 Apr 25;34(16):5364-71.

40. Cardoso FC, Castro J, Grundy L, Schober G, Garcia-Caraballo S, Zhao $\mathrm{T}$, et al. A spider-venom peptide with multitarget activity on sodium and calcium channels alleviates chronic visceral pain in a model of irritable bowel syndrome. Pain. 2020 Feb 1;162(2):569-81.

41. Deuis JR, Dekan Z, Inserra MC, Lee TH, Aguilar MI, Craik DJ, et al. Development of a $\mu \mathrm{O}$-Conotoxin Analogue with Improved Lipid Membrane Interactions and Potency for the Analgesic Sodium Channel NaV1.8. J Biol Chem. 2016 May 27;291(22):11829-42.

42. Sato K, Raymond C, Martin-Moutot N, Sasaki T, Ohtake A, Minami K, et al. Binding of Ala-scanning analogs of omega-conotoxin MVIIC to $\mathrm{N}$ - and P/Q-type calcium channels. FEBS Lett. 2000 Mar 10;469(2-3):147-50. 